\title{
Increasing Threats to Snow Leopard Survival in Pakistan
}

\author{
Shahid Ahmad ${ }^{1,2}$, Ghulam Nabi ${ }^{2 *}$, Charlotte E. Hacker ${ }^{3}$, Ivan Igorevich Strelnikov ${ }^{4}$ and \\ Xiaofeng Luan $^{1 *}$ \\ ${ }^{1}$ Beijing Forestry University, Beijing, China, ${ }^{2}$ Ministry of Education Key Laboratory of Molecular and Cellular Biology, Key \\ Laboratory of Animal Physiology, Biochemistry and Molecular Biology of Hebei Province, College of Life Sciences, Hebei \\ Normal University, Shijiazhuang, China, ${ }^{3}$ Duquesne University, Pittsburgh, PA, United States, ${ }^{4}$ State Institution Donetsk \\ Botanical Garden Donetsk, Donetsk, Ukraine
}

Keywords: snow leopard, conservation, Pakistan, threats, illegal poaching

\section{OPEN ACCESS}

Edited by:

Pavel Kindlmann

Charles University, Czechia

Reviewed by:

Bikram Shrestha,

Czech Academy of Sciences, Czechia

David Mallon,

Manchester Metropolitan University,

United Kingdom

${ }^{*}$ Correspondence:

Ghulam Nabi

ghulamnabiqau@gmail.com

Xiaofeng Luan

luanxiaofeng@bjfu.edu.cn

Specialty section:

This article was submitted to

Conservation and Restoration

Ecology,

a section of the journal

Frontiers in Ecology and Evolution

Received: 20 November 2021

Accepted: 25 January 2022

Published: 24 February 2022

Citation:

Ahmad S, Nabi G, Hacker CE

Strelnikov II and Luan X (2022)

Increasing Threats to Snow Leopard

Survival in Pakistan.

Front. Ecol. Evol. 10:818798.

doi: 10.3389/fevo.2022.818798
The snow leopard (Panthera uncia; Figure 1) is an iconic threatened species native to high mountain landscapes and remains scarcely distributed across 12 Central and Southern Asian countries, including Pakistan (Figure 2; McCarthy et al., 2017). A population of 2,710-3,386 individuals is estimated globally (McCarthy et al., 2017), with a decreasing trend primarily due to poaching (McCarthy et al., 2017), retaliation, habitat loss (Li et al., 2020), and climate change (Farrington and Li, 2016). Since 2008, there have been an estimated 221-450 ( 4/week) snow leopard poaching incidents annually (Nowell et al., 2016; WWF, 2016). Over $90 \%$ of these incidents occur in five countries, including China, India, Mongolia, Tajikistan, and Pakistan (WWF, 2016).

Despite their numbers being between 200-420 individuals in Pakistan (Kazmi et al., 2021), snow leopard survival in the country is at higher risk for six main reasons. (I) Poaching; In Khunjerab National Park (KNP) and surrounding conservancies, 13 snow leopards have been killed in the last 7 years (Rashid et al., 2021); however, an expert survey indicates that the situation is much worse than the reported annual statistics suggest (Nowell et al., 2016). (II) Competition for primary prey; Growing populations of feral dogs compete with snow leopards for primary natural prey (markhor; Capra falconeri). In Chitral Gol National Park (CGNP; $77.4 \mathrm{~km}^{2}$ area) alone, feral dogs have killed 392 markhors in the past 15 years (2006-2020; Khattak et al., 2021), while data for ibex (Capra sibirica) and markhor mortality are not available in other regions. (III) Illegal killing of primary prey; The illegal harvest of ibex and markhor for meat is very high in Pakistan's snow leopard habitats. Recently, over 100 ibex were killed for influential and government officials (Mir, 2020). Due to intense unchecked hunting of markhor, its population has catastrophically declined from 2,868 individuals in 2019 to $<800$ individuals at present (Ahmad and Nabi, 2022). (IV) Trophy Hunting (TH); The current TH program of snow leopard prey in Pakistan runs counter to the ultimate objective of conservation e.g., TH inside national parks and increasing negative attitudes among local residents toward snow leopard (Rashid et al., 2021). (V) Conflict between humans and snow leopards; Snow leopards frequently attack livestock and kill dozens of animals (Geo News, 2021). In retaliation, many snow leopards are killed every year by pastoralists seeking to protect their livelihoods (WWF, 2016). (VI) Environmental factors and lack of research; Climate change, habitat degradation, fragmentation and isolation, overwhelming environmental threats from the China-Pakistan Economic Corridor (CPEC; Nabi et al., 2018, 2019), lack of resources and cooperation from the wildlife department for research, and inaccessibility and geopolitical sensitivity of the research area additionally compromise snow leopard conservation.

Illegal hunting and poaching of snow leopards are widespread activities, owing to snow leopard parts being commonly used for Traditional Chinese Medicine (TCM; Coghlan et al., 2015; Byard, 2016). The snow leopard is listed in Appendix I of the Convention on International Trade in Endangered Species of Wild Fauna and Flora (CITES; Checklist of CITES Species, 2022). Illegal wildlife trade, if not controlled, maybe facilitated to major hubs in other southeast Asian countries 
through the CPEC of the Belt and Road Initiative (BRI; Farhadinia et al., 2019). The promotion of TCM is a central component of BRI (Hughes et al., 2020) and could enhance demand for threatened wildlife species products. Therefore, it is essential to strictly monitor the illegal trade of wildlife and wildlife products in this region and adjoining countries.

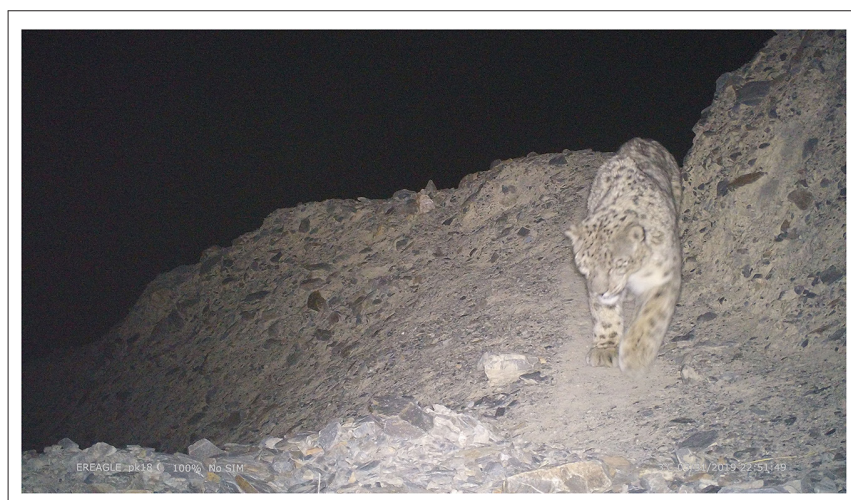

FIGURE 1 | Snow leopard photo captured at the Khunjerab National Park, Pakistan. (Photo credit; Shahid Ahmad).
Feral dogs are causing a stark decline in the primary prey of the snow leopards. The numerical increase and geometrical expansion of the feral dog population (Khattak et al., 2021) should be regulated using castration and sterilization techniques. Community awareness of food waste disposal and collaborative teamwork between municipal and wildlife departments could further help regulate the feral dog population in CGNP and neighboring regions.

If the extensive and unregulated killing of primary prey by feral dogs, hunters, and poachers continues, the snow leopards being a top "specialist predator," may lack necessary food resources. Consequently, snow leopards would be more likely to kill livestock, which would, in turn, exacerbate poaching and retaliatory killing. Considering the drastic decline in primary prey, it is in the species' best interests to revisit the current $\mathrm{TH}$ policy. Strict action is required against the influential government officials and hunters to discourage and better regulate ibex and markhor hunting. Although most herders nowadays are aware of the threatened status of the snow leopard, they still have negative attitudes toward the species due to their role in livestock deaths. Pastoralist financial losses are either not compensated or very little financial assistance is provided (Geo News, 2021). The government's responsibility is to fully support local people.

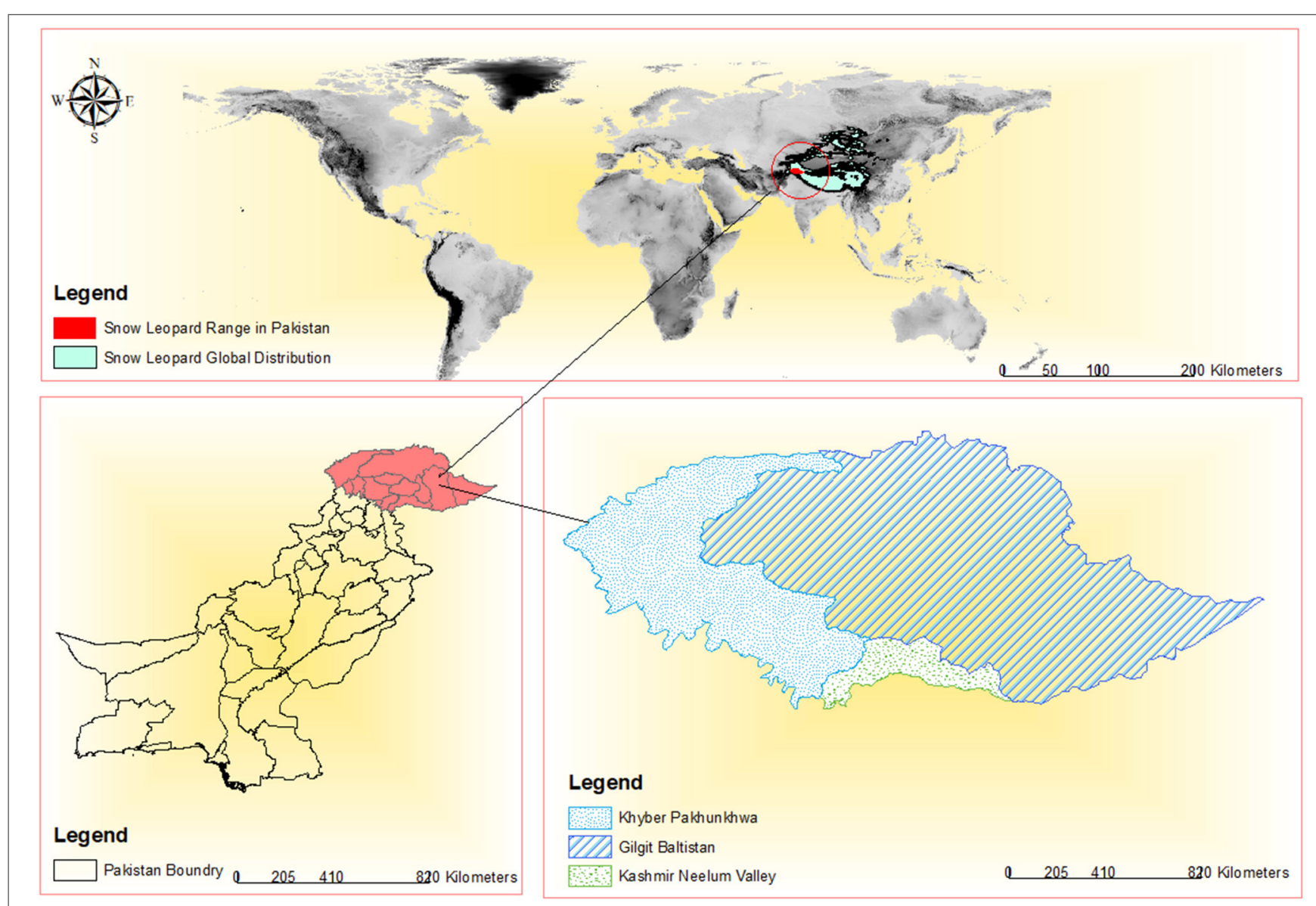

FIGURE 2 | Snow leopard distribution range in Pakistan (IUCN). 
Jobs in ecotourism, wildlife, and environmental conservation departments may help in alleviating dependence on pastoralist economies in Pakistan.

The CPEC and climate change could have ecological effects on local biodiversity (Nabi et al., 2017; Lashari et al., 2021) that could significantly impact the conservation and management of wildlife in Pakistan's fragile ecosystems. More studies are needed to understand these impacts. For this, sufficient funds are needed to equip researchers and wildlife department officials to access areas of snow leopard habitat that are largely unexplored for research, patrolling, and management. There is also a need to deeply investigate the availability of food resources for snow leopards and ecophysiological studies using non-invasive samples (e.g., hairs, fecal samples).

\section{REFERENCES}

Ahmad, S., and Nabi, G. (2022). Pakistan's markhor population in decline. Science 375, 153. doi: $10.1126 /$ science.abn 0745

Byard R. W. (2016). Traditional medicines and species extinction: Another side to forensic wildlife investigation. Forensic Sci. Med. Pathol. 12, 125-127. doi: 10.1007/s12024-016-9742-8

Checklist of CITES Species (2022). CITES Secretariat, Geneva, Switzerland and UNEP-WCMC, Cambridge, United Kingdom. Available online at: https://checklist.cites.org/\#/en (accessed January 11, 2022).

Coghlan, M. L., Maker, G., Crighton, E., Haile, J., Murray, D. C., White, N. E., et al. (2015). Combined DNA, toxicological and heavy metal analyses provides an auditing toolkit to improve pharmacovigilance of traditional Chinese medicine (TCM). Sci. Rep. 5, 17475. doi: 10.1038/srep 17475

Farhadinia, M. S., Maheshwari, A., Nawaz, M. A., Ambarl,i H., Gritsina, M. A., Koshkin, M. A., et al. (2019). Belt and Road Initiative may create new supplies for illegal wildlife trade in large carnivores. Nat. Ecol. Evol. 3, 1267-1268. doi: 10.1038/s41559-019-0963-6

Farrington, J. D., and Li, J. (2016). "Climate change impacts on snow leopard range," in Snow Leopards, eds T. McCarthy and D. Mallon (Academic Press), 85-95. doi: 10.1016/B978-0-12-802213-9.00008-0

Geo News (2021). Snow Leopard Kills Over 50 Cattle in Hunza. Available online at: https://www.geo.tv/latest/351464-snow-leopard-kills-over-50-cattle-animalsin-hunza (accessed 25 October 2021)

Hughes, A. C., Lechner, A. M., Chitov, A., Horstmann, A., Hinsley, A., Tritto, A., et al. (2020). Horizon scan of the Belt and Road Initiative. Trends Ecol. Evol. 3, 583-593. doi: 10.1016/j.tree.2020.02.005

Kazmi, F. A., Shafique, F., Hassan, M., Khalid, S., Ali, N., Akbar, N., et al. (2021). Ecological impacts of climate change on the snow leopard (Panthera unica) in South Asia. Braz. J. Biol. 31, 82. doi: 10.1590/1519-6984.24 0219

Khattak, R. H., Xin, Z., Ahmad, S., Bari, F., Khan, A., Nabi, G., et al. (2021). Feral dogs in Chitral gol national park, Pakistan: a potential threat to the future of threatened Kashmir Markhor (Capra falconeri cashmiriensis). Braz. J. Biol. 20, 83. doi: 10.1590/1519-6984.24 5867

Lashari, A. H., Li, W., Hassan, M., Nabi, G., Mabey, P. T., Islam, M. M., et al. Biodiversity governance and management in Pakistan: A way forward through the China-Pakistan economic corridor. Pol. J. Environ. Stud. (2021) 30:2589-2596. doi: 10.15244/pjoes/126321

Li, J., Weckworth, B. V., McCarthy, T. M., Liang, X., Liu, Y., Xing, R., et al. (2020). Defining priorities for global snow leopard conservation

\section{AUTHOR CONTRIBUTIONS}

SA and GN conceived the study and drafted the manuscript. $\mathrm{CH}$ and IS critically reviewed the manuscript. XL funded and critically reviewed the manuscript. All authors listed have made a substantial, direct, and intellectual contribution to the work and approved it for publication.

\section{ACKNOWLEDGMENTS}

We are thankful to the Ministry of Science and Technology of the People's Republic of China (Research and application of key techniques on endangered species conservation and prediction of forest fire and pests in response to climate change, 2013BAC09B00) for support.

landscapes. Biol. Conserv. 241, 108387. doi: 10.1016/j.biocon.2019.10 8387

McCarthy, T., Mallon, D., Jackson, R., Zahler, P., and McCarthy, K. (2017) Panthera Uncia. The IUCN Red List of Threatened Species.

Mir, S. (2020). Killer of over 100 Ibex Arrested in Gilgit-Baltistan. The Express Tribune. Available online at: https://tribune.com.pk/story/2235465/killer-100ibex-arrested-gilgit-baltistan (accessed on 25 October, 2021)

Nabi, G., Ali, M., Khan, S. and Kumar, S. (2019). The crisis of water shortage and pollution in Pakistan: risk to public health, biodiversity, and ecosystem. Environ Sci Pollut Res Int. 26, 10443-10445. doi: 10.1007/s11356-019-04483-w

Nabi, G., Khan, S., Ahmad, S., Khan, A., and Siddique, R. (2017). China-Pakistan Economic Corridor (CPEC): an alarming threat to the biodiversity of Northern Pakistan. Biodivers. Conserv. 26, 3003-3004. doi: 10.1007/s10531-017-1402-0

Nabi, G., Ullah, S., Khan, S., Ahmad, S., and Kumar, S. (2018). ChinaPakistan Economic Corridor (CPEC): melting glaciers-a potential threat to ecosystem and biodiversity. Environ. Sci. Pollut. Res. 25, 3209-3210. doi: $10.1007 /$ s11356-017-1151-3

Nowell, K., Li, L., Paltsyn, M., and Sharma, R. K. (2016). An Ounce of Prevention: Snow Leopard Crime Revisited. Traffic. 2016, Cambridge.

Rashid, W., Shi, J., Dong, S., and Sultan, H. (2021). Issues and opportunities associated with trophy hunting and tourism in Khunjerab National Park, Northern Pakistan. Animals 10, 597. doi: 10.3390/ani10040597

WWF (2016). Hundreds of Snow Leopards Poached Each Year. Available online at: https://wwf.panda.org/wwf_news/?282170/Hundreds-of-snow-leopardspoached-each-year (accessed 25 October, 2021).

Conflict of Interest: The authors declare that the research was conducted in the absence of any commercial or financial relationships that could be construed as a potential conflict of interest.

Publisher's Note: All claims expressed in this article are solely those of the authors and do not necessarily represent those of their affiliated organizations, or those of the publisher, the editors and the reviewers. Any product that may be evaluated in this article, or claim that may be made by its manufacturer, is not guaranteed or endorsed by the publisher.

Copyright (C) 2022 Ahmad, Nabi, Hacker, Strelnikov and Luan. This is an open-access article distributed under the terms of the Creative Commons Attribution License (CC $B Y)$. The use, distribution or reproduction in other forums is permitted, provided the original author(s) and the copyright owner(s) are credited and that the original publication in this journal is cited, in accordance with accepted academic practice. No use, distribution or reproduction is permitted which does not comply with these terms. 